\title{
Modelling of compacted graphite cast iron solidification - Discussion of microstructure
}

\section{parameters}

\author{
*Jacques Lacaze', Urko de la Torre ${ }^{2}$, Jon Sertucha ${ }^{2}$, Anna Regordosa ${ }^{2}$ \\ 1. Centre Inter-universitaire de Recherche et d'Ingénierie des Matériaux (CIRIMAT), Université de Toulouse, Toulouse, France \\ 2. Fundación AZTERLAN, Durango, Spain
}

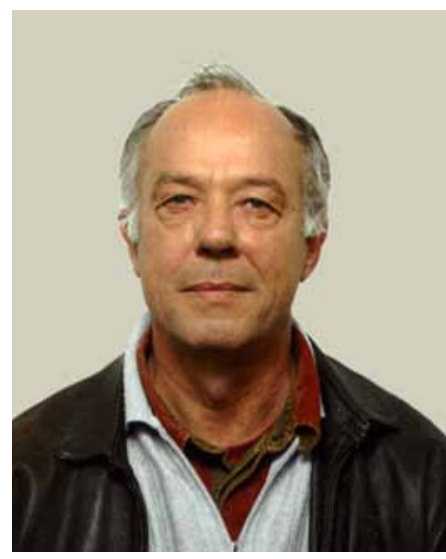

*Jacques Lacaze

Male, born in 1955, senior scientist, Ph.D. He had been working first in the field of solidification of metallic alloys such as aluminium and nickelbase alloys, and later started a longstanding work on cast irons during a one year post-doctor season in Stockholm, Sweden. His research interest was focused on microstructure formation during solidification and solid-state transformations, and extended to mechanical properties and oxidation as he moved to the CIRIMAT laboratory in Toulouse, France, in 1994. For the past couple of years, he has also been working on brazing of aluminium alloys. His academic research has led to the publication of 170 peer reviewed journal articles and 100 conference papers.

E-mail: jacques.lacaze@ensiacet.fr

Received: 2020-04-08

Accepted: 2020-04-10
Abstract: A melt maintained for hours in a press pour unit allowed the following changes over time from spheroidal graphite to compacted graphite iron by casting thermal cups at regular time intervals. This provided extensive experimental information for checking the possibility of simulating solidification of compacted graphite irons by means of a microstructure modelling approach. During solidification, compacted graphite develops very much as lamellar graphite but with much less branching. On this basis, a simulation of the thermal analysis records was developed which considers solidification proceeding in a pseudo binary Fe-C system. The simulated curves were compared with the experimental ones obtained from three representative alloys that cover the whole microstructure change during the holding of the melt. The most relevant result is that the parameter describing branching capability of graphite is the most important for reproducing the minimum eutectic temperature and the recalescence which are so characteristic of the solidification of compacted graphite cast irons.

Key words: compacted graphite irons; thermal analysis; stable eutectic; metastable eutectic; simulation

CLC numbers: TG146.21; Document code: A; Article ID: 1672-6421(2020)02-144-06

$\mathrm{D}$ uring a long period of time, what is now called compacted graphite was described as being worm-like. However, detailed 2D metallographic examinations of deepetched samples ${ }^{[1,2]}$, as well as tomographic studies ${ }^{[3,4]}$, have shown that graphite in a compacted graphite iron (CGI) mainly consists of a few spheroids and inter-connected lamellae with some round bumps. Accordingly, most of the solidification of CGI must consist of the growth of eutectic cells quite like lamellar graphite cells. However, it has already been noticed that, at given casting conditions, compacted graphite is much coarser than flake graphite, and it was suggested this is related to a much lower capability of the former to branch during growth as compared to the latter ${ }^{[5,6]}$. On this basis, solidification of compacted graphite iron could be simulated as it has been done for lamellar graphite iron ${ }^{[7]}$, though adjusting the parameter related to graphite branching. This contribution compares experimental and calculated cooling curves of hyper-eutectic uninoculated CGI and discusses the few parameters needed to simulate their solidification, namely those parameters describing graphite nucleation, growth of compacted graphite cells, and growth of the metastable eutectic.

\section{Experimental approach}

The samples analyzed in this work were produced from a melt maintained in an $8 \mathrm{t}$ capacity nitrogen pressurized pouring unit (press-pour) for several hours as described previously ${ }^{[8]}$. The initial amount of magnesium in the melt was $0.030-0.040 \mathrm{wt} . \%$ so as to give spheroidal graphite castings. During holding, the magnesium content slowly 
decreased leading eventually to castings with compacted graphite. Every 20 minutes or so, a coupon for chemical analysis and two thermal analysis (TA) cups were cast. One of the TA cups was empty before pouring the melt while the other one contained a commercial inoculant. Nineteen castings were thus successively obtained which were then identified with a letter from A to S and a subscript "uninoc" and "inoc" for uninoculated and inoculated alloys, respectively. It was found that the thermal records of the uninoculated alloys were much more diverse and thus contained much more information than those with inoculation. Accordingly, three of the nineteen uninoculated alloys were selected, being the most representative of the microstructure evolution with holding time.

Table 1 lists the composition of alloys C, E and Q which were the three alloys selected in the present work. It is seen that the contents of $\mathrm{Mg}, \mathrm{Ce}$ and $\mathrm{La}$ decrease significantly and that the contents of $\mathrm{C}$ and $\mathrm{Si}$ diminish slightly as well, while the amounts of all other elements do not change. In addition, Table 1 lists the carbon equivalent (CE) and the calculated stable $\left(T_{\mathrm{EUT}}\right)$ and metastable $\left(T_{\mathrm{EW}}\right)$ eutectic temperatures $\left({ }^{\circ} \mathrm{C}\right)^{[9]}$.

Table 1: Composition and carbon equivalent (CE) of the Alloys C, $E$ and $Q$ (wt.\%), and calculated stable $\left(T_{\mathrm{EUT}}\right)$ and metastable $\left(T_{\mathrm{EW}}\right)$ eutectic temperatures $\left({ }^{\circ} \mathrm{C}\right)$

\begin{tabular}{ccccccccccccc} 
Alloy & $\mathbf{C}$ & $\mathrm{Si}$ & $\mathrm{Mn}$ & $\mathrm{Cr}$ & $\mathrm{Ni}$ & $\mathrm{Cu}$ & $\mathrm{Mg}$ & $\mathrm{Ce}$ & $\mathrm{La}$ & $\mathrm{CE}$ & $T_{\mathrm{EUT}}$ & $T_{\mathrm{EW}}$ \\
C & 3.75 & 2.45 & 0.63 & 0.049 & 0.028 & 0.85 & 0.038 & 0.0120 & 0.0037 & 4.52 & $1,165.1$ & $1,119.4$ \\
E & 3.72 & 2.42 & 0.63 & 0.048 & 0.030 & 0.84 & 0.035 & 0.0100 & 0.0027 & 4.48 & $1,165.3$ & $1,119.8$ \\
$\mathbf{Q}$ & 3.66 & 2.40 & 0.62 & 0.049 & 0.028 & 0.83 & 0.013 & 0.0023 & 0.0007 & 4.41 & $1,165.2$ & $1,120.0$ \\
\hline
\end{tabular}

\section{Experimental results}

The three cooling curves in Fig. 1 show the same features characterized by a two-step solidification as follows:

(1) A short arrest at a temperature which increases with holding time between $1,140{ }^{\circ} \mathrm{C}$ and $1,150{ }^{\circ} \mathrm{C}$;

(2) A main arrest which starts at a minimum temperature before recalescence, $T_{\mathrm{E}, \mathrm{min}}$, which decreased with holding time, from Alloy C to Alloy Q.

This figure also plots the average temperature for the stable, $T_{\mathrm{EUT}}$, and metastable, $T_{\mathrm{EW}}$, eutectics to support the discussion below. As the alloys are hypereutectic, the first arrest may be associated with the formation of austenite when the solidification path during primary precipitation of graphite reaches the metastable extrapolation of the austenite liquidus. It is noticeable that the temperature of this arrest, denoted here $T_{\mathrm{EN}}$, is far below $T_{\mathrm{EUT}}$. The shape of the cooling curves between $T_{\mathrm{EN}}$ and $T_{\mathrm{E} \text {,min }}$ is seen to be somehow the same for all the three curves meaning that the overall kinetics of solidification is nearly the same. For samples $C_{\text {uninoc }}$ and $\mathrm{E}_{\text {uninoc }}$, the thermal arrest during bulk eutectic solidification has the same appearance and is characterized by a significant recalescence. This suggests that it proceeds in the same way for both alloys. In contrast, bulk eutectic solidification of sample $\mathrm{Q}_{\text {uninoc }}$ proceeds below $T_{\mathrm{EW}}$ and is characterized by a very limited change in temperature with, however, an abrupt small recalescence (red arrow in Fig. 1).

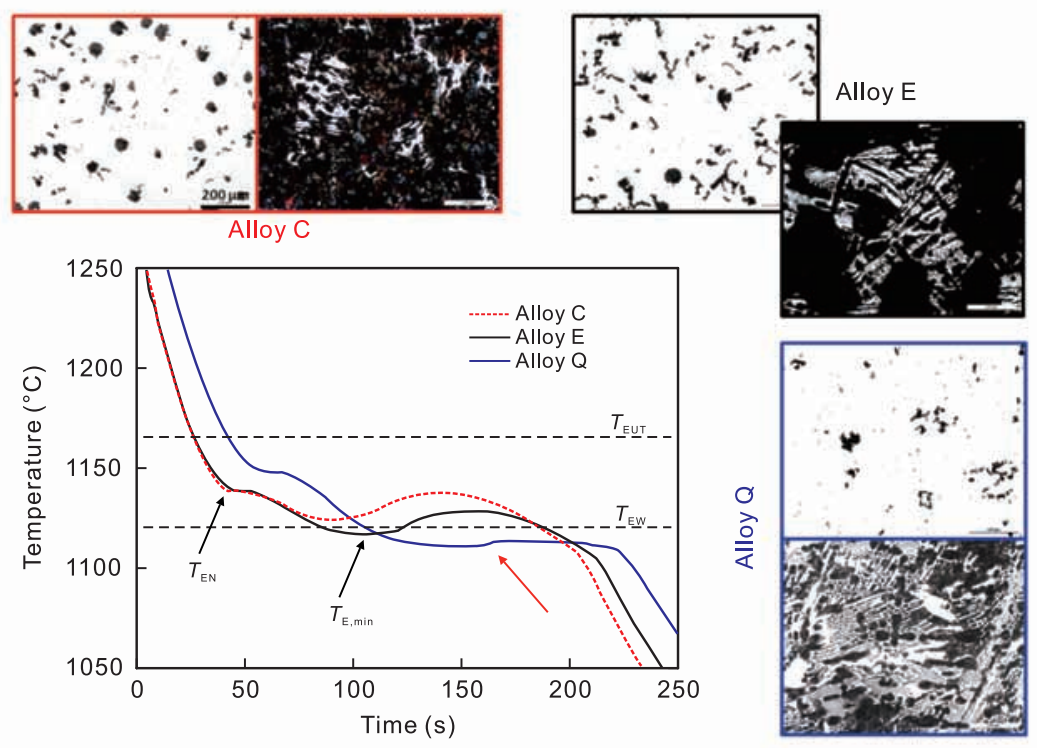

Fig. 1: Experimental cooling curves of the three selected samples $\left(C_{\text {uninoc }}, E_{\text {uninoc }}\right.$ and $\left.Q_{u n i n o c}\right)$ and related optical micrographs before and after nital etching. The scale of the micrographs is the same for all and is shown in the upper left one 
In Fig. 1, the micrographs before etching show that the number of graphite particles decreases with holding time, and those after etching show the amount of carbides increases. It is noticed that carbides must have appeared in sample $\mathrm{C}_{\text {uninoc }}$ at the end of solidification as the main eutectic plateau is located above $T_{\mathrm{EW}}$. The similarity of the cooling curves of samples $\mathrm{C}_{\text {uninoc }}$ and $\mathrm{E}_{\text {uninoc }}$ suggests that cementite also appeared in this latter alloy after the main plateau. In contrast, carbides in sample $\mathrm{Q}_{\text {uninoc }}$ may have appeared at any time during bulk eutectic solidification which proceeded totally below $T_{\mathrm{EW}}$, but this precipitation could well be related to the recalescence mentioned above and will be discussed later.

\section{Modelling bases}

The model briefly described below considers solidification proceedings in a pseudo-binary $\mathrm{Fe}-\mathrm{C}$ system which accounts for the effects of $\mathrm{Si}, \mathrm{Mn}$ and $\mathrm{Cu}$ contents on the temperature and composition defining the lines of the phase diagram. Solidification of cast irons is quantitatively described by writing the appropriate mass balances following the work by Lesoult et al. ${ }^{[10]}$ on spheroidal graphite cast irons. For describing the eutectic reaction in the present study, spheroidal graphite eutectic cells are replaced by compacted graphite cells of radius $R$ whose growth law is written according to Jones and Kurz ${ }^{[7]}$ :

$$
\frac{d R}{d t}=\frac{(\Delta T)^{2}}{\left(\frac{1}{\varphi}+\varphi\right)^{2} \cdot a \cdot b}
$$

where $t$ is time, $\Delta T$ is the undercooling with respect to the equilibrium eutectic temperature, $T_{\mathrm{EUT}}, a$ and $b$ are constants evaluated by Jones and Kurz, $a=2.3 \mu \mathrm{m} \cdot \mathrm{K}$ and $b=0.080 \mathrm{~K} \cdot \mathrm{s} \cdot \mu \mathrm{m}^{-2}$, and $\varphi$ characterizes the capability of the faceted graphite phase to branch.

For an ideal regular eutectic between two non-faceted phases, $\varphi$ should be 1 , while it has been proposed to be 2.5 for Fe-C graphite/austenite eutectic ${ }^{[1]}$. Jones and Kurz ${ }^{[7]}$ could reproduce their experimental results of directionally solidified lamellar graphite iron with $\varphi$ set to 3.9, while Zou $\mathrm{Jie}^{[12]}$ found a value of 6.5 for equiaxed solidification of an Fe-C-Si alloy. Zou Jie ${ }^{[12]}$ suggested that part of the difference with directional solidification is due to the expanding nature of the eutectic cells during equiaxed solidification. In the case of compacted graphite cells, the protuberances formed on the primary graphite precipitates then developed without much branching. Thus, the distance between them increases as the size of the compacted graphite cells increases. This suggested $\varphi=\varphi^{0}+R / R_{\mathrm{GE}}$, where $R_{\mathrm{GE}}$ is the initial size of the cell, and to limit the change of $\varphi$ from the initial value of $\varphi^{0}=2.5$ to some maximum value, $\varphi_{\max }$, equal to or lower than 10 , at which point branching of graphite lamellae is anyway expected because of the high undercooling developed between the lamellas ${ }^{[1]}$.
In the case of hyper-eutectic alloys, the solidification path during primary deposition was calculated assuming spheroidal graphite precipitates following a nucleation law given as $N_{\mathrm{V}}=A_{1} \cdot\left(\Delta T_{\mathrm{LG}}\right)$, where $N_{\mathrm{V}}$ is the volume number of cells, $A_{1}$ is the nucleation constant and $\Delta T_{\mathrm{LG}}$ is the undercooling with respect to the graphite liquidus ${ }^{[10]}$. When the extrapolation of the austenite liquidus is reached, the number of graphite particles is set constant at the value which has been reached. An equivalent diameter of the graphite particles is calculated which is then used as the initial size for the compacted graphite cells, $R_{\mathrm{GE}}$. Solidification proceeds further by growth of eutectic cells and off-eutectic austenite which may also dissolve in order for the solidification path to adhere to the extrapolation of the austenite liquidus ${ }^{[10]}$.

As seen above, cooling of uninoculated alloys in TA cups shows metastable solidification competes with stable solidification. Growth of ledeburite is to be described as spherical cells of radius $R_{\mathrm{W}}$ using the data from Hillert and Subba Rao ${ }^{[13]}$, which is very close to the value later found by Jones and Kurz ${ }^{[7]}$ :

$$
\frac{d R_{\mathrm{W}}}{d t}=30 \cdot\left(\Delta T_{\mathrm{EW}}\right)^{2}
$$

where $R_{\mathrm{W}}$ is in $\mu \mathrm{m}$ and $\Delta T_{\mathrm{EW}}$ is the undercooling with respect to $T_{\mathrm{EW}}$. The number of metastable eutectic cells was in all cases set to $0.5 \mathrm{~mm}^{-3}$.

The solidification process of the thermal cups was described assuming their temperature was homogeneous at any time during the cooling process. For each time step of calculation, the calculated change of the solid fraction, $V^{\mathrm{S}}$, was thus introduced in the following heat balance:

$$
\rho \cdot V / A \cdot\left(C_{\mathrm{p}} \cdot \frac{d T}{d t}-\Delta H \cdot \frac{d V^{\mathrm{S}}}{d t}\right)=-\sqrt{\Delta} \cdot\left(T-T^{0}\right) \cdot t^{-0.5}
$$

Where $\rho$ and $C_{\mathrm{p}}$ are, respectively, the density and the heat capacity of the metal at temperature $T, \Delta H$ is the latent heat of fusion of the metal, $\Delta$ is a quantity characteristic of the mould, and $T^{0}$ is the ambient temperature. $V$ is the volume of metal having an outer surface area $A$, and $V / A$ is the so-called casting modulus. The same equation is used without the second term on the left hand side for describing liquid and solid cooling. All data used in the present calculations are listed in Table 2. During solidification, the specific heat $C_{\mathrm{p}}$ and the density $\rho$ were calculated as a weighted average of the solid and liquid values. Impingement of eutectic cells was accounted for using the correction factor $\left(1-V^{\mathrm{S}}\right)^{2}$.

\section{Simulation results}

According to preliminary calculations, the start temperature of the metal at the time of pouring, $T_{\text {pour }}$, was set to the first recorded temperature plus $30^{\circ} \mathrm{C}$. The $A_{1}$ value used to describe 
Table 2: Values of parameters used for calculations

\begin{tabular}{|c|c|c|c|c|c|c|}
\hline $\begin{array}{l}V I A \\
(\mathrm{~m})\end{array}$ & $\begin{array}{c}\sqrt{\Delta} \\
\left(\mathrm{J} \cdot \mathrm{m}^{-2} \cdot \mathrm{K}^{-1} \cdot \mathrm{s}^{-0.5}\right)\end{array}$ & $\begin{array}{c}C_{\mathrm{p}}^{\text {liquid }} \\
\left(\mathrm{J} \cdot \mathrm{K}^{-1} \cdot \mathrm{kg}^{-1}\right)\end{array}$ & $\begin{array}{c}C_{\mathrm{p}}^{\text {solid }} \\
\left(\mathrm{J} \cdot \mathrm{K}^{-1} \cdot \mathrm{kg}^{-1}\right)\end{array}$ & $\begin{array}{c}\rho^{\text {liquid }} \\
\left(\mathbf{k g} \cdot \mathbf{m}^{-3}\right)\end{array}$ & $\begin{array}{l}\rho^{\text {austenite }} \\
\left(\mathbf{k g} \cdot \mathbf{m}^{-3}\right)\end{array}$ & $\begin{array}{l}\rho^{\text {graphite }} \\
\left(\mathbf{k g} \cdot \mathrm{m}^{-3}\right)\end{array}$ \\
\hline 0.009 & $\begin{array}{l}728 \text { before solidification } \\
1,215 \text { after solidification }\end{array}$ & 920 & 750 & 6,800 & 7,000 & 2,200 \\
\hline
\end{tabular}

primary graphite nucleation was determined so as to give close fit to the experimental cell number. Table 3 lists the values of $T_{\text {pour }}$ and $A_{1}$ used in the calculations for each alloy, the measured values of $D_{\text {Cell }}$ and $N_{\mathrm{A}}$, and the experimental values of

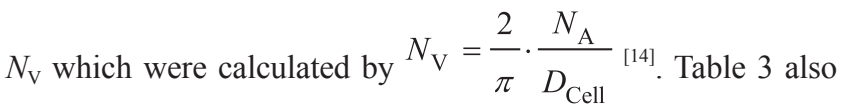
lists the experimental values of $f_{\text {carbides, }}$, and the predicted values of $N_{\mathrm{V}}$ and $f_{\text {carbides. }}$. Unless specified, all calculations were made with $\varphi_{\max }=10$.
Figure 2 (a) compares the experimental cooling curve for the uninoculated Alloy $\mathrm{C}$ to the calculated one without considering the possibility for formation of metastable eutectic. It is seen that the main eutectic peak is quite well reproduced but that the beginning of the curves differs significantly. As a matter of fact, austenite is predicted to appear at $T_{\mathrm{EN}}=1,147.7^{\circ} \mathrm{C}$ (red arrow) leading afterwards to a constant slope indicative of a regular growth of solid. In contradistinction, the experimental curve shows a thermal arrest starting at about $1,140{ }^{\circ} \mathrm{C}$ with a marked but short plateau.

Table 3: Values used for calculations for each of the three alloys and predicted $\boldsymbol{N}_{\mathrm{v}}$ and $\boldsymbol{f}_{\text {carbides }}$ values

\begin{tabular}{ccccccccc} 
Alloy & $\begin{array}{c}\boldsymbol{T}_{\text {pour }} \\
\left({ }^{\circ} \mathrm{C}\right)\end{array}$ & $\begin{array}{c}\mathbf{A}_{1} \\
\left(\mathrm{~mm}^{-3} \cdot \mathbf{K}^{-1}\right)\end{array}$ & $\begin{array}{c}\boldsymbol{D}_{\text {cell }} \\
(\mathrm{mm})\end{array}$ & $\begin{array}{c}\mathbf{N}_{\mathrm{A}} \\
\left(\mathrm{mm}^{-2}\right)\end{array}$ & $\begin{array}{c}\text { Experimental } \\
\mathbf{N}_{\mathrm{v}}\left(\mathrm{mm}^{-3}\right)\end{array}$ & $\begin{array}{c}\text { Predicted } \\
\mathbf{N}_{\mathrm{v}}\left(\mathrm{mm}^{-3}\right)\end{array}$ & $\begin{array}{c}\text { Measured } \\
\boldsymbol{f}_{\text {carbides }}(\%)\end{array}$ & $\begin{array}{c}\text { Predicted } \\
\boldsymbol{f}_{\text {carbides }}(\%)\end{array}$ \\
\hline C & 1,320 & 0.5 & 0.32 & 24.0 & 47.8 & 43.7 & 9 & - \\
E & 1,324 & 0.1 & 0.54 & 6.4 & 7.5 & 6.95 & 9 & 33.5 \\
Q & 1,373 & 0.08 & 0.36 & 1.5 & 2.6 & 3.1 & 42 & $53.4(25.6)^{*}$
\end{tabular}

*The value between bracket is that obtained when ledeburite appears after a time delay.

(a)

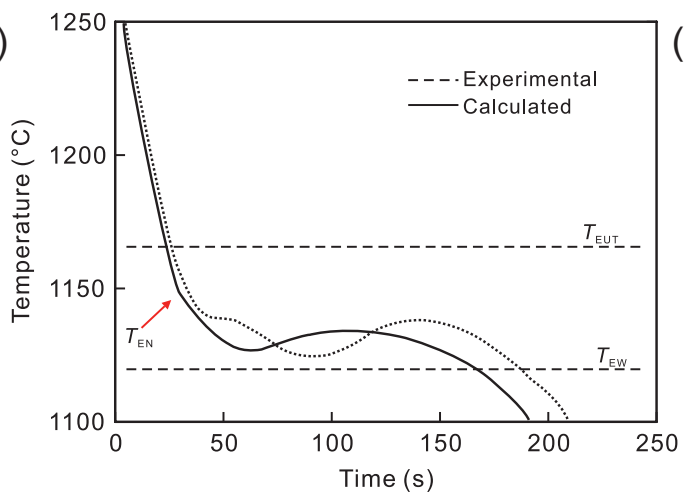

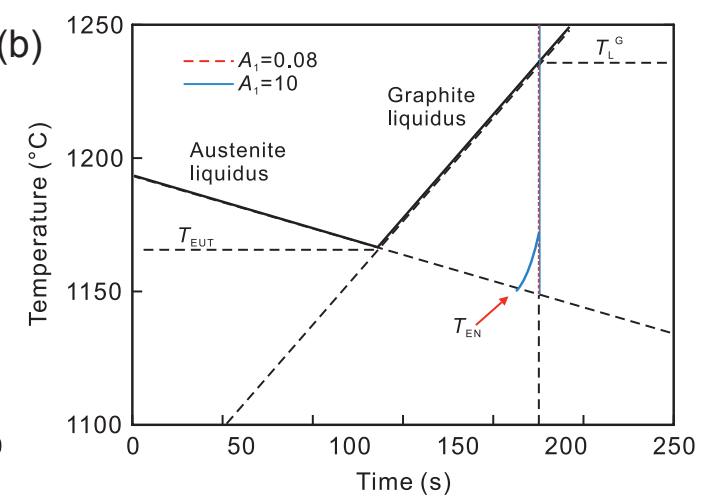

Fig. 2: Comparison of calculated and experimental cooling curves for the uninoculated Alloy $C$ (a), and effect of $A_{1}$ value on the solidification path during primary graphite precipitation (b). The red arrow in (a) indicates the slope change associated with appearance of austenite at the calculated $T_{\mathrm{EN}}$ temperature; similarly, $T_{\mathrm{EN}}$ in (b) indicates the corresponding end of primary graphite precipitation when austenite is predicted to appear

It was first thought that the discrepancy at the beginning of solidification could originate in the description of the primary deposition of graphite which controls the temperature at which is reached the metastable extrapolation of the austenite liquidus. Accordingly, $A_{1}$ was changed from 0.08 to $10 \mathrm{~mm}^{-3} \cdot \mathrm{K}^{-1}$ leading to a change in $N_{\mathrm{V}}$ from 3 to $760 \mathrm{~mm}^{-3}$, which covered the full range of the measured values. Figure 2 (b) shows the calculated primary solidification path plotted on the isopleth $\mathrm{Fe}-\mathrm{C}$ section of the phase diagram, i.e., corresponding to the alloy content in $\mathrm{Si}, \mathrm{Mn}$ and $\mathrm{Cu}$. For $A_{1}=0.08 \mathrm{~mm}^{-3} \cdot \mathrm{K}^{-1}$, the volume fraction of graphite precipitated during primary deposition is so low that the carbon content in the liquid remains nearly unchanged and equal to the alloy nominal value (vertical red dotted line). The austenite liquidus is thus attained at a temperature of $1,147.7^{\circ} \mathrm{C}$. By increasing $A_{1}$ to $10 \mathrm{~mm}^{-3} \cdot \mathrm{K}^{-1}$, it is seen that precipitation of graphite starts curving the solidification path towards the graphite liquidus only by the end of primary deposition (blue solid curve). Accordingly, the calculated $T_{\mathrm{EN}}$ value at $1,150.1{ }^{\circ} \mathrm{C}$ is not much higher than that for lower $A_{1}$ value. To force the liquid composition to follow more closely the graphite liquidus, much higher values of $A_{1}$ would be required which would correspond to highly inoculated alloys. It thus appears that the discrepancy between calculated and experimental $T_{\mathrm{EN}}$ values must be due to an undercooling of the austenite phase which is well-known 
experimentally ${ }^{[15]}$. This can be related to the time needed for austenite dendrites nucleated at the surface of the TA cup to reach the centre. Note that the increase of the experimental value of $T_{\mathrm{EN}}$ between Alloys $\mathrm{C}$ and $\mathrm{Q}$ shown in Fig. 1 relates to the decrease in the alloy carbon content with holding time and thus to a move to the left of the solidification path in Fig. 2 (b).

Figure 3 (a) compares the experimental cooling curve for the uninoculated Alloy E to the calculated curve when ledeburite is considered. It is seen that the main eutectic plateau of the calculated curve is at a nearly constant temperature apart from a very small and short recalescence at the beginning. This must be related to rapid growth of ledeburite which totally overtakes the solidification in the stable system. Owing to the fact that such a plateau did not appear in the experimental curve, calculations were performed again without considering the precipitation of ledeburite. The result is shown in Fig. 3 (b) where it is seen that the predicted shape is as the experimental one, but with a lower $T_{\mathrm{E}, \min }$ and recalescence values than observed. The calculations were performed again with a lower $\varphi_{\max }$ value of 7.5, and the curve is also shown in Fig. 3 (b). It is seen that decreasing $\varphi_{\max }$ significantly increases $T_{\mathrm{E}, \min }$ and marginally increases the recalescence value. In the present case, an intermediate value of $\varphi_{\max }$ would give a perfect fit between predicted and observed $T_{\mathrm{E}, \min }$ and recalescence values.
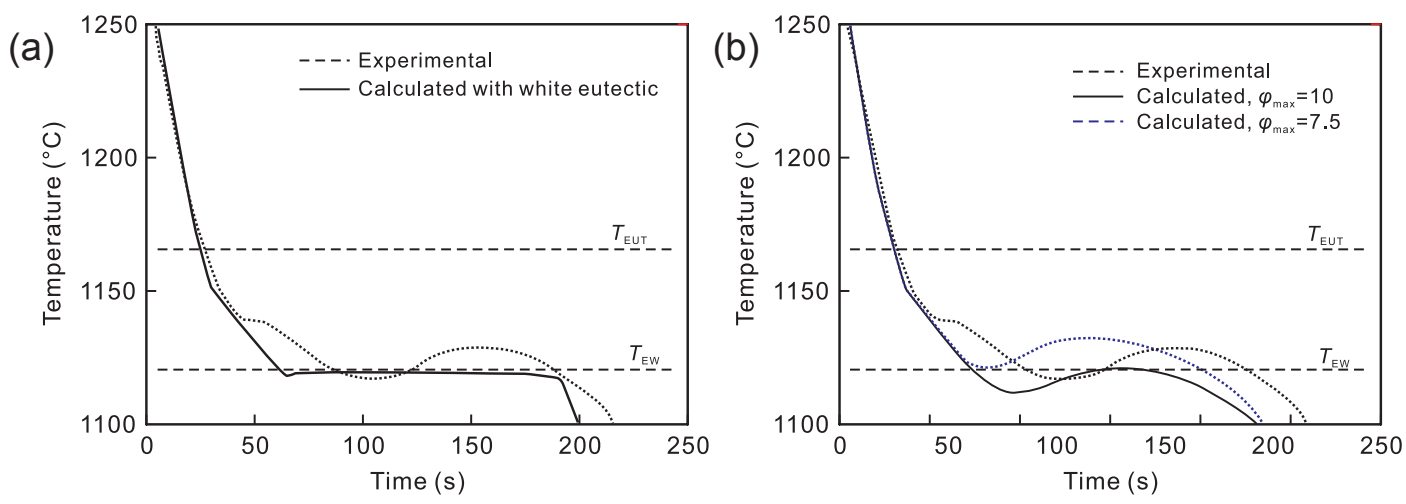

Fig. 3: Comparison of calculated and experimental cooling curves for uninoculated Alloy E:

(a) calculation performed accounting for ledeburite formation; (b) calculations performed for two values of $\varphi_{\max }$ and without ledeburite precipitation

Finally, Fig. 4 compares the predicted and experimental cooling curves for the uninoculated Alloy Q. The first calculation was carried out with ledeburite appearing as soon as the temperature fell below $T_{\mathrm{EW}}$ and this leads to the thin red solid line which shows a long and flat eutectic plateau that does not resemble the experimental curve. This makes evident that the small but abrupt recalescence seen at about $160 \mathrm{~s}$ on the experimental curve certainly represents the appearance of ledeburite. Accordingly, formation of ledeburite was delayed in a second calculation which was shown with the thick black solid line. It is then seen that the smooth evolution of the cooling curve before recalescence as well as the amplitude of

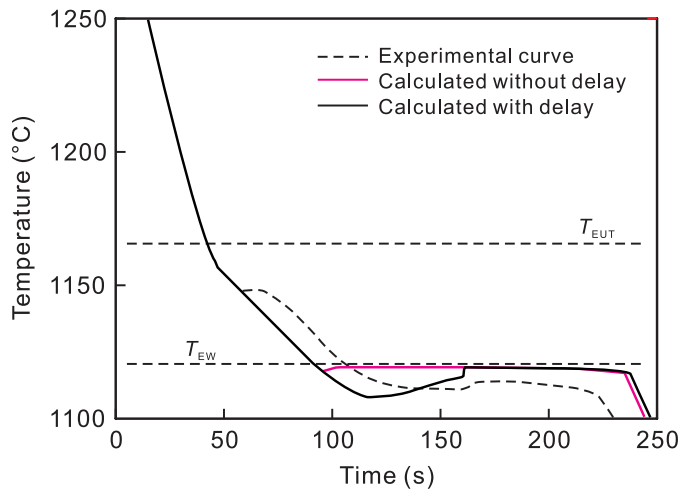

Fig. 4: Comparison of experimental and calculated cooling curves for the uninoculated Alloy Q. Ledeburite appearance was calculated either without (thin red solid line) or with (thick black solid line) a time delay recalescence are quite well reproduced even though the growth law used for ledeburite may give elevated growth rates. It may be postulated that the delay which has been introduced relates to the time needed for ledeburite to nucleate close to the thermocouple junction.

\section{Conclusion}

It is shown that the solidification characteristics of CGI as observed with cooling curves may be represented by using a modelling approach derived from that used for lamellar graphite irons. The parameter describing the branching capability of graphite lamellae in eutectic cells appears to be the most sensitive parameter to describe the maximum undercooling and the recalescence of the bulk eutectic reaction of CGI. Dedicated experiments would be needed to explore the effect of residual magnesium content on this parameter. Some marginal improvements to the present approach could be made concerning the description of austenite formation and growth of ledeburite.

\section{References}

[1] Loper C R, Voigt R C, Yang J R, et al. Use of the scanning electron microscope in studying growth mechanisms in cast irons. AFS Trans., 1982, 89: 549-552.

[2] Den Xijun, Zhu Peiyue, Liu Qifu. Structure and formation of vermicular graphite. Mat. Res. Soc. Symp. Proc., 1985, 34: $141-150$. 
[3] Chuang C, Singh D, Kenesei $P$, et al. 3D quantitative analysis of graphite morphology in high strength cast iron by highenergy X-ray tomography. Scripta Mater., 2015, 106: 5-8.

[4] Salomonsson K, Jarfors A E W. Three-dimensional microstructural characterization of cast iron alloys for numerical analyses. In: Proc. SPCI-XI, edited by A. Diószegi, V. L. Diaconu and A. E. W. Jarfors, Trans. Tech. Pub., Zurich, 2018, 925: 427-435

[5] Lacaze J, Sertucha J. Some paradoxical observations about spheroidal graphite degeneracy. China Foundry, 2018, 15 (6): 457-463.

[6] Lacaze J, Connétable D, Castro de Roman M J. Effects of impurities on graphite shape during solidification of spheroidal graphite cast ions. Materialia, 2019, 8: 100471, DOI: 10.1016/ j.mtla.2019.100471.

[7] Jones $\mathrm{H}$, Kurz W. Relation of interphase spacing and growth temperature to growth velocity in $\mathrm{Fe}-\mathrm{C}$ and $\mathrm{Fe}-\mathrm{Fe}_{3} \mathrm{C}$ eutectic alloys. Z. Metallknde, 1981, 72: 792-797.

[8] Regordosa A, de la Torre U, Loizaga A, et al. Microstructure changes during solidification of cast irons - Effect of chemical composition and inoculation on competitive spheroidal and compacted graphite growth. Int. J. Metalcasting, DOI : 10.1007/s40962-019-00389-y.
[9] Castro M, Herrera M, Cisneros M M, et al. Simulation of thermal analysis applied to the description of the solidification of hypereutectic SG cast irons. Int. J. Cast Met. Res., 1999, 11: 369-374.

[10] Lesoult G, Castro M, Lacaze J. Solidification of spheroidal graphite cast irons - I. Physical modelling. Acta Mater., 1998, 46: 983-995.

[11] Trivedi R and Kurz W. Microstructure selection in eutectic binary systems. In: Solidification processing of eutectic alloys, Ed. D. M. Stefanescu, G. J. Abbaschian and R. J. Bayuzick, The Metallurgical Society, USA, 1988: 3-34.

[12] Zou Jie. Simulation of eutectic solidification, Ph.D thesis \#774, 1989, Ecole Polytechnique Fédérale de Lausanne, Switzerland.

[13] Hillert M, Subba Rao V V. Grey and white solidification of cast iron. The Institute of Metals, 1969: 204-211.

[14] Coster M, Chermant J L. Handbook of image analysis. Presses du CNRS, 1989. (In French)

[15] Heine R W. Austenite liquidus, carbide eutectic and undercooling in process control of ductile base iron. AFS. Trans., 1995: 199-206. 